\title{
Relationship between bread and obesity ${ }^{\text {is }}$
}

\author{
Luis Serra-Majem $^{1,2 *}$ and Inmaculada Bautista-Castaño ${ }^{1,2}$ \\ ${ }^{1}$ Research Institute of Biomedical and Health Sciences, University of Las Palmas de Gran Canaria, Las Palmas de Gran \\ Canaria, Spain \\ ${ }^{2}$ CIBER Fisiopatología de la Obesidad y Nutrición (CIBERobn), Instituto de Salud Carlos III (ISCIII), Madrid, Spain \\ (Submitted 4 March 2014 - Final revision received 16 August 2014 - Accepted 3 September 2014)
}

\section{Abstract}

Some studies have indicated that promoting the Mediterranean diet pattern as a model of healthy eating may help to prevent weight gain and the development of overweight/obesity. Bread consumption, which has been part of the traditional Mediterranean diet, has continued to decline in Spain and in the rest of the world, because the opinion of the general public is that bread fattens. The present study was conducted to assess whether or not eating patterns that include bread are associated with obesity and excess abdominal adiposity, both in the population at large or in subjects undergoing obesity management. The results of the present review indicate that reducing white bread, but not whole-grain bread, consumption within a Mediterranean-style food pattern setting is associated with lower gains in weight and abdominal fat. It appears that the different composition between whole-grain bread and white bread varies in its effect on body weight and abdominal fat. However, the term 'whole-grain bread' needs to be defined for use in epidemiological studies. Finally, additional studies employing traditional ways of bread production should analyse this effect on body-weight and metabolic regulation.

Key words: Mediterranean diet: Refined bread: Whole-grain bread: Obesity: Abdominal obesity

Several epidemiological studies investigating the relationship between diet and general or abdominal obesity have obtained inconsistent results ${ }^{(1)}$.

The characteristics of the Mediterranean diet include the following: high consumption of olive oil; high consumption of legumes; high consumption of unrefined cereals (including bread); high consumption of fruits; high consumption of vegetables; moderate consumption of dairy products, mostly as cheese and yogurt; moderate to high consumption of fish; low consumption of meat and meat products; moderate consumption of wine ${ }^{(2,3)}$. Some studies have indicated that promoting the Mediterranean diet pattern as a model of healthy eating may help to prevent weight gain and the development of obesity ${ }^{(4,5)}$.

Within the cereal group, bread is an important dietary constituent from a nutritional point of view. However, a long-standing belief held by the general public is that bread fattens. This encourages many people to restrict or even eliminate bread from their diet. Thus, consumption of bread, which has been part of the traditional Spanish diet (the Mediterranean diet), has continued to fall in Spain and in the rest of the world ${ }^{(6)}$. However, although bread consumption has been decreasing over the past decades, the global epidemic of obesity has been increasing ${ }^{(7)}$.

Some studies have specifically investigated the associations between cereal consumption and BMI or abdominal fat. They showed inverse associations with anthropometric variables for consumption of whole-grain cereals, but yielded conflicting results for consumption of refined cereals ${ }^{(8)}$. Factors such as postprandial insulin responses, gastric emptying after consuming a high-glycaemic index (GI) meal and

\footnotetext{
Abbreviations: GI, glycaemic index; PREDIMED, PREvención con DIeta MEDiterránea; VAT, visceral adipose tissue; WC, waist circumference.

*Corresponding author: L. Serra-Majem, fax +34928458949, email 1serra@dcc.ulpgc.es

2 Publication of these papers was supported by unrestricted educational grants from Federación Española de Sociedades de Nutrición, Alimentación y Dietética (FESNAD), International Nut and Dried Fruit Council (INC), International Union of Nutritional Sciences (IUNS), Fundación Iberoamericana de Nutrición (FINUT), Centro de Investigación Biomédica en Red de la Fisiopatología de la Obesidad y Nutrición (CIBERobn) and Centro Interuniversitario di Ricerca sulle Culture Alimentari Mediterranee (Ciiscam). The papers included in this supplement were invited by the Guest Editors and have undergone the standard journal formal review process. They may be cited. The Guest Editors declare that Salas-Salvadó is a nonpaid member of the World Forum for Nutrition Research and Dissemination of the International Nut and Dried Fruit Council. Angel Gil is President of the Fundación Iberomericana de Nutrición, which is a non-paid honorary position. Lluis Serra-Majem is the President of the Scientific Committee of the Mediterranean Diet Foundation and Scientific Director of the CIISCAM (Centro Interuniversitario di Ricerca sulle Culture Alimentari Mediterranee), Universita La Sapienza di Roma which are both non-paid, honorary positions. Goretti Guasch is the Executive Director and Member of the Executive Committee of the International Nut and Dried Fruit Council, which is a paid position. Mònica Bulló declares no conflict of interest.
} 
other factors could be implicated in a potential differential effect of refined $v$. whole-grain cereals on adiposity ${ }^{(9)}$.

The present study was conducted to assess whether or not eating patterns that include bread as well as bread consumption itself (refined and whole-grain bread) were associated with overall obesity and abdominal adiposity, both in the general population and in subjects undergoing obesity management. Additionally, the objective of the present study was to address the relationship between bread consumption and changes in weight or waist circumference (WC) over time. Moreover, we considered it interesting to investigate whether bread consumption had been decreasing and if so, which food groups were being consumed in its place.

This knowledge would assist efforts in developing public health messages and recommendations regarding healthy eating habits that help individuals to maintain an appropriate BMI and to prevent abdominal obesity. Achieving better nutritional status for the general population would be an additional beneficial outcome.

\section{Scientific evidence}

We have recently published a systematic review about the influence of bread intake on body weight and abdominal fat distribution $^{(10)}$. The literature search strategy was designed to identify original studies conducted on the association between bread intake and variations in ponderal status. The search was limited to English- or Spanish-language publications from a 30-year period (1978-2008). To identify publications in scientific journals, the search was conducted in MEDLINE and in the Spanish Medical Index (Índice Médico Español).

Articles identified in the initial search were eligible for inclusion if the following criteria were met: (1) the research

Table 1. Classification of the most relevant studies segregated according to the influence of bread consumption on ponderal status ${ }^{(10)}$

\begin{tabular}{|c|c|c|c|}
\hline $\begin{array}{l}\text { First author } \\
\text { and year }\end{array}$ & $\begin{array}{l}\text { Differentiate } \\
\text { bread type? }\end{array}$ & Study conclusions & Relationship \\
\hline & & Conclusions from cross-sectional studies & \\
\hline $\begin{array}{l}\text { Tillotson et al. } \\
\quad(1997)^{(11)}\end{array}$ & No & $\begin{array}{l}\text { No relationship was observed between bread and cereal } \\
\text { intake and BMI }\end{array}$ & None \\
\hline $\begin{array}{l}\text { Jacobs et al. } \\
\qquad(1998)^{(12)}\end{array}$ & Yes & $\begin{array}{l}\text { Food group that included whole-meal bread was } \\
\text { associated with a lower BMl and WHR; group that } \\
\text { included refined bread was associated with a slight } \\
\text { WHR increase }\end{array}$ & $\begin{array}{l}\text { Group of food items that included whole-meal } \\
\text { bread was beneficial } \\
\text { Group of food items that included refined } \\
\text { bread increased WC }\end{array}$ \\
\hline $\begin{array}{l}\text { Greenwood et al. } \\
\qquad(2000)^{(13)}\end{array}$ & Yes & $\begin{array}{l}\text { Food group that included whole-meal bread was inversely } \\
\text { related to BMI }\end{array}$ & $\begin{array}{l}\text { Group of food items that included whole-meal } \\
\text { bread was beneficial }\end{array}$ \\
\hline $\begin{array}{l}\text { Cleveland et al. } \\
\qquad(2000)^{(14)}\end{array}$ & Yes & $\begin{array}{l}\text { Whole-meal bread within the consumption of grains with } \\
\text { fibre was associated with lower excess weight }\end{array}$ & $\begin{array}{l}\text { Group of food items that included whole-meal } \\
\text { bread was beneficial }\end{array}$ \\
\hline $\begin{array}{l}\text { Cho et al. } \\
\qquad(2003)^{(15)}\end{array}$ & Yes & $\begin{array}{l}\text { Food group that included bread at breakfast was } \\
\text { associated with a lower BMI }\end{array}$ & Beneficial \\
\hline $\begin{array}{l}\text { Moreira \& Padrão } \\
\qquad(2006)^{(16)}\end{array}$ & No & $\begin{array}{l}\text { No relationship was observed between the food group that } \\
\text { included bread and the risk of presenting with obesity } \\
\text { Conclusions from prospective cohort studies }\end{array}$ & None \\
\hline $\begin{array}{l}\text { Schulz et al. } \\
\qquad(2002)^{(17)}\end{array}$ & No & $\begin{array}{l}\text { Food group that did not include bread was associated with } \\
\text { weight change over time }\end{array}$ & None \\
\hline $\begin{array}{l}\text { Schulz et al. } \\
\qquad(2005)^{(18)}\end{array}$ & Yes & $\begin{array}{l}\text { Food group that included whole-meal bread was predictive } \\
\text { of avoiding weight gain }\end{array}$ & Beneficial \\
\hline $\begin{array}{l}\text { Liu et al. } \\
\qquad(2003)^{(19)}\end{array}$ & Yes & $\begin{array}{l}\text { Whole-meal bread included in the food group was } \\
\text { associated with no weight gain over time; the opposite } \\
\text { for refined bread }\end{array}$ & $\begin{array}{l}\text { Food group that included whole-meal bread was } \\
\text { beneficial } \\
\text { Food group that included refined bread was } \\
\text { associated with weight gain }\end{array}$ \\
\hline $\begin{array}{l}\text { Halkjaer et al. } \\
\qquad(2004)^{(20)}\end{array}$ & Yes & $\begin{array}{l}\text { High intake of refined bread was associated with increased } \\
\text { WC in females }\end{array}$ & $\begin{array}{l}\text { Food group that included refined bread was } \\
\text { associated with increased WC } \\
\text { No relationship was observed for the food } \\
\text { group that included whole-meal bread }\end{array}$ \\
\hline $\begin{array}{l}\text { Togo et al. } \\
\qquad(2004)^{(21)}\end{array}$ & Yes & $\begin{array}{l}\text { Bread was not predictive of changes in ponderal status } \\
\text { or development of obesity }\end{array}$ & None \\
\hline $\begin{array}{l}\text { Koh-Banerjee } \\
\quad \text { et al. }(2004)^{(22)}\end{array}$ & Yes & $\begin{array}{l}\text { Whole-meal bread included in the food group was } \\
\text { predictive (negatively associated) of ponderal gain; } \\
\text { no influence was observed for refined bread }\end{array}$ & $\begin{array}{l}\text { Food group that included whole-meal bread was } \\
\text { beneficial } \\
\text { No relationship was observed for the food } \\
\text { group that included refined bread }\end{array}$ \\
\hline $\begin{array}{l}\text { Halkjaer et al. } \\
\qquad(2006)^{(23)}\end{array}$ & Yes & $\begin{array}{l}\text { Refined bread was associated with WC gain in females. } \\
\text { This association was not observed for whole-meal bread }\end{array}$ & $\begin{array}{l}\text { Food group that included refined bread was } \\
\text { associated with increased WC } \\
\text { No relationship was observed for the food } \\
\text { group that included whole-meal bread }\end{array}$ \\
\hline $\begin{array}{l}\text { Stamler \& } \\
\text { Dolecek } \\
(1997)^{(24)}\end{array}$ & No & $\begin{array}{l}\text { Conclusions from intervention studies } \\
\text { In the intervention group, the percentage of energy from } \\
\text { bread and cereals was increased in individuals } \\
\text { belonging to the group of greater weight loss }\end{array}$ & Beneficial \\
\hline
\end{tabular}

WC, waist circumference; WHR, waist:hip ratio. 
was original work; (2) the study assessed bread consumption (any definition explicitly included in the consumption of food items, nutritional habits, dietary patterns, percentage of energy, and carbohydrates or fibre derived from bread); (3) the outcome variables of the study included weight status and/or abdominal adiposity. Restrictions regarding study design, subject age, sample size or period of followup were not employed.

The studies meeting the inclusion criteria were classified into three groups according to the study design: crosssectional studies ( $n$ 22); prospective cohort studies ( $n$ 11); intervention studies ( $n$ 5).

Studies with a large number of subjects ( $>5000$ individuals or in the case of longitudinal design, a sample size of $>2000$ individuals) and a follow-up period of at least 5 years were considered highly relevant and selected for closer examination. A total of fourteen studies met these criteria. Table 1 summarises the results of the study regarding the influence of the consumption of food groups that included bread on ponderal status (favourable, unfavourable or neutral).

Among the six highly relevant studies of cross-sectional design ${ }^{(11-16)}$, two that did not distinguish the type of bread in food groups, Tillotson et al. ${ }^{(11)}$ and Moreira \& Padrão ${ }^{(16)}$, did not find a relationship between ponderal status and dietary patterns that included bread consumption. Among the studies that identified the type of bread, only Jacobs et $a l .{ }^{(12)}$ found an unfavourable relationship between dietary patterns that included white (refined) bread and waist measurements. The dietary patterns that included wholegrain bread $^{(13-15)}$ showed systematic beneficial outcomes. Seven prospective cohort studies were also included in this group $^{(17-23)}$. In two of these studies ${ }^{(17,21)}$, bread was not in the food group that was related to weight change over time; the 2002 study of Schulz et al. ${ }^{(17)}$ did not distinguish between different types of bread. The remaining five studies observed a beneficial effect, in general, of food groups that included whole-grain bread in terms of preventing ponderal gain over the long term ${ }^{(18,19,22)}$. In three of these five studies, an unfavourable effect was also observed ${ }^{(19,20,23)}$, with a gain in adiposity related to the consumption of food groups that included white bread. In two of these three studies with undesirable effects, increases in waist size were recorded ${ }^{(20,23)}$. With reference to intervention studies, only a few controlled studies examined the effect of consuming food groups containing bread and cereal on weight reduction or long-term weight maintenance. Comparisons of the specific effects of food groups that included whole-grain products $v$. groups that included refined bread or cereals were also scarce. The only study of note was that conducted by Stamler \& Dolecek $^{(24)}$, in which the intervention for inducing weight loss was more effective when the percentage of energy from bread and cereals was increased.

We also analysed 2213 participants at a high risk of CVD from the PREvención con DIeta MEDiterránea (PREDIMED) trial to assess the association between changes in the consumption of bread and increases in weight and WC over time. Dietary habits were assessed with a validated FFQ

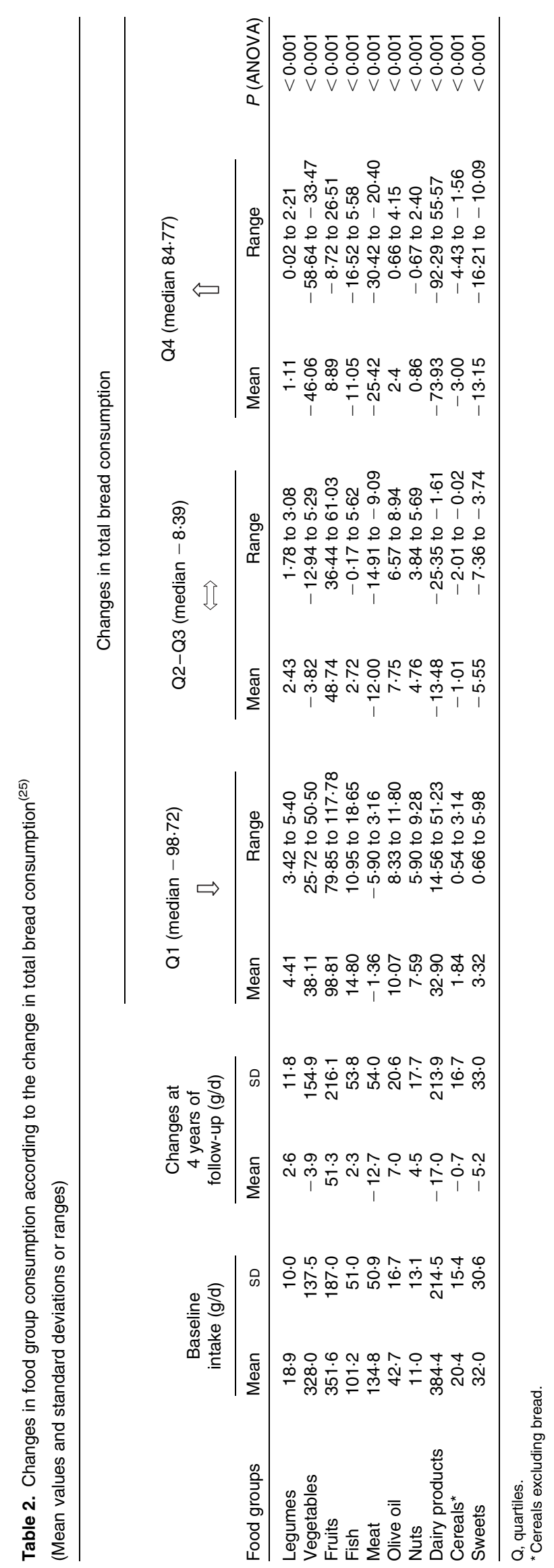


at baseline and repeatedly every year during 4 years of followup. Using multivariate models to adjust for covariates, longterm changes in weight and $\mathrm{WC}$ according to the quartiles of change in energy-adjusted white and whole-grain bread consumption were calculated ${ }^{(25)}$.

The PREDIMED trial is the first large randomised controlled trial for the primary prevention of CVD that allocates participants to one of three dietary patterns. These consisted of two Mediterranean type diets (Med-diet) with different fat sources, mixed nuts or virgin olive oil, and one low-fat diet (control group) ${ }^{(26,27)}$. The study population was composed of men aged between 55 and 80 years and women aged between 60 and 80 years with no previously documented CVD, but at a high risk of CVD.

The outcomes after 4 years of follow-up were: (1) changes in food group consumption according to the change in total bread consumption; (2) change in body weight after 4 years of follow-up; (3) change in WC after 4 years of follow-up; (4) risk of gaining or losing more than $2 \mathrm{~kg}$ of weight; (5) risk of gaining or losing more than $2 \mathrm{~cm}$ of WC.

Table 2 shows the association between changes in total bread consumption and changes in food groups after 4 years of follow-up. The participants who decreased their consumption of total bread increased their consumption of vegetables, dairy products, fish, cereals (other than bread) and sweets. Similarly, those who increased their bread consumption decreased the consumption of these groups of foods. Moreover, meat consumption declined in the follow-up period, but this decrease was higher among those participants who increased their bread consumption.

In the cross-sectional analysis, we did not find a significant dose-response relationship between baseline consumption of each type of bread and anthropometric variables.

Table 3 shows the average weight gain (in $\mathrm{kg}$ ) and waist gain (in $\mathrm{cm}$ ) according to the quartiles of change in total, white and whole-grain bread consumption during the 4 years of follow-up, adjusted for potential confounders.

In general, increases in total bread consumption were associated with more weight gain (mean weight change of $0.16 \mathrm{~kg}$ after 4 years in the lowest quartile and of $0.82 \mathrm{~kg}$ in the highest quartile, $P$ for trend $=0.019$ ) and with more WC gain (mean waist change of $1 \mathrm{~cm}$ after 4 years in the lowest quartile and of $2.34 \mathrm{~cm}$ in the highest quartile, $P$ for trend $<0 \cdot 001)$. For white bread, the results were very similar for weight (mean weight change of $0 \cdot 14 \mathrm{~kg}$ after the follow-up period in the lowest quartile and of $0.90 \mathrm{~kg}$ in the highest quartile, $P$ for trend $=0.003$ ) and for WC gain (mean waist change of $1.11 \mathrm{~cm}$ in the lowest quartile and of $2.39 \mathrm{~cm}$ in the highest quartile, $P$ for trend $<0 \cdot 001$ ). No significant dose-response relationship was observed for the change in whole-bread consumption and anthropometric measures. The adjustment for total dietary fibre intake had little effect on these results.

Finally, changes in the consumption of any type of bread during 4 years of follow-up were not associated with the risk of gaining more than $2 \mathrm{~cm}$ in WC or more than $2 \mathrm{~kg}$ in weight among the PREDIMED participants. When compared with the subjects who were in the lowest quartile of change 
in white bread consumption, those in the highest quartile showed a significant reduction in the odds of losing weight $(>2 \mathrm{~kg})$ and WC $(>2 \mathrm{~cm})$ of 33 and $36 \%$, respectively. Moreover, a significant inverse dose-response relationship was found for the increment in the consumption of white bread and the probability of losing weight $(P$ for trend $=0.021)$ and WC ( $P$ for trend $=0 \cdot 009$ ).

\section{Summary of scientific evidence for the influence of bread consumption on general and abdominal obesity}

\section{Systematic review}

(1) The majority of studies following a food pattern that included bread were not associated with an increase in ponderal status.

(2) Consumption of whole-grain bread was more beneficial than refined bread, especially in relation to abdominal fat.

(a) Whole-grain bread: does not influence weight gain.

(b) White bread: possible relationship with excess abdominal fat.

\section{PREvención con Dleta MEDiterránea study}

(1) The results showed that over 4 years, participants in the highest quartile of the change in white bread intake gained $0.76 \mathrm{~kg}$ more in weight than those in the lowest quartile and $1.28 \mathrm{~cm}$ more in WC than those in the lowest quartile.

(2) No significant dose-response relationships were observed for the change in whole-bread consumption and anthropometric measures.

(3) Gaining weight $(>2 \mathrm{~kg})$ and gaining WC $(>2 \mathrm{~cm})$ during the follow-up was not associated with an increase in bread consumption. However, participants in the highest quartile of changes in white bread intake had a $33 \%$ reduction in the odds of losing weight $(>2 \mathrm{~kg})$ and a $36 \%$ reduction in the odds of reducing $\mathrm{WC}(>2 \mathrm{~cm})$.

\section{Hypotheses on the mechanism of action whereby bread consumption influences general and abdominal obesity}

We do not know with precision what the mechanism is as whole-grain bread could prevent increased WC and body weight, and a dietary pattern low in refined bread might help to prevent body-weight increase and abdominal fat accumulation.

The possible mechanisms involved in the action of whole grains (including bread) are ${ }^{(28,29)}$ :

(1) Energy density

(2) GI

(3) Dietary fibre

(4) Gut microbiota.

\section{Energy density}

The lower energy density of products based on whole-grain cereals compared with those made with refined cereals, as well as the satiating effect of whole-grain products, could both play an important role in body-weight regulation. In the case of bread intake, although both types of bread (whole-grain bread and refined bread) have similar energy content, whole-grain bread has the greatest satiating power ${ }^{(30)}$. This may influence the decreased energy intake observed from other foods.

\section{Glycaemic index}

Lower plasma glucose and insulin responses to whole-grain cereal intake can also contribute to body-weight regulation. Lower plasma glucose and insulin responses have been observed in diabetic and non-diabetic subjects after the ingestion of a low-GI diet containing pumpernickel bread, pasta and legumes, compared with a high-GI diet containing refined bread and potatoes. In fact, several studies have shown that the consumption of foods or meals with a low GI has a higher satiating effect than those with a high GI, irrespective of the evaluation method utilised (direct or indirect) and the possible contribution of some confounders (palatability and fibre content ${ }^{(31)}$. The lower rate of nutrient digestion and absorption typical of low-GI foods seems to stimulate the release of gastrointestinal peptides related to satiation and satiety signals. Therefore, the intact food structure that accounts for the lower GI of whole-grain cereals can contribute to body-weight regulation.

Du et al. ${ }^{(32)}$ carried out a prospective cohort study in 89432 Europeans aged between 20 and 78 years, who were monitored for an average of 6.5 years to assess the effect of the GI and glycaemic load on body weight and WC. The study did not find an effect on the change in body weight. The GI (but not the glycaemic load) was moderately associated with a larger WC. McKeown et $a l^{\left({ }^{33)}\right.}$ conducted a study in a sample of the 'Framingham Heart Study cohort', and they found that a higher intake of whole-grain foods was associated with lower visceral adipose tissue (VAT) in adults, whereas a higher intake of refined grains was associated with higher VAT. In this study, fasting insulin concentrations were observed to attenuate the associations between refined grain intake, but not whole grain intake, and VAT volume, perhaps suggesting an intermediary role of insulin in the positive relationship between refined grain intake and VAT volume. The additional adjustment for insulin did not affect the relationship observed between whole grain intake and VAT.

Finally, Giacco et al. ${ }^{(34)}$, in 2013, designed an intervention study evaluating glucose and insulin metabolism in response to long-term consumption of rye and whole wheat compared with a diet containing the same amount of refined cereal foods in individuals with the metabolic syndrome from two European locations (Kuopio, Finland/Naples, Italy). Overall, 146 participants were assigned to a diet based on whole-grain (whole-grain group) or on refined cereal products (control group), each lasting for a duration of 12 weeks. At the end 
of the intervention, insulin sensitivity indices and secretion did not change significantly in the whole-grain and control groups when compared with baseline, and no differences between the two groups were observed.

\section{Dietary fibre}

The potential mechanism or mechanisms by which whole grains may be related to regional adiposity are speculative. Whole grains are rich in fermentable carbohydrates such as dietary fibre, resistant starch and oligosaccharides. Cereal fibre influences body weight by multiple mechanisms depending on intrinsic properties, hormonal effects and intestinal fermentation. Specifically, intrinsic properties concern the ability of soluble fibre to bind to water and form a viscous solution that delays gastric emptying and intestinal transit, and limits glucose absorption, thus leading to a lower blood glucose response ${ }^{(35)}$. The hormonal effects of fibre are mediated by insulin and gastrointestinal hormones. Fibre decreases insulin secretion and, consequently, reduces the risk of reactive hypoglycaemia during the post-absorption period, thus promoting satiety and satiation, increasing fat oxidation and decreasing fat storage. Fibre also influences gut hormone secretion that, independently of plasma glucose response, acts on satiety or modifies glucose homeostasis. Cholecystokinin, secreted by small-bowel cells, stimulates pancreatic secretion, modulates gastric emptying and stimulates the hypothalamic centre of satiety $^{(36)}$.

In the previously mentioned study of McKeown et al. ${ }^{(33)}$, added bran and dietary fibre was also adjusted for in the analysis. The association between higher intake of wholegrain foods with lower VAT and higher intake of refined grains with higher VAT persisted, suggesting that these were not the mediating attributes of the diet related to body fat distribution

We carried out a previously mentioned study ${ }^{(25)}$ in a sample of PREDIMED subjects evaluating the influence of bread intake and WC. We did not find any differences in the relationship between higher intakes of refined bread and increases in WC, adjusting for dietary fibre.

\section{Gut microbiota}

A further mechanism by which whole grains may influence body-weight regulation is via a prebiotic effect modulating the intestinal flora. Available evidence, primarily from investigations in animal models, suggests that the gut microbiota affects nutrient acquisition and energy regulation. Microbiota composition has also been shown to differ in lean $v$. obese animals and human subjects ${ }^{(37)}$. Among the possible mechanisms of this relationship, of particular interest is the hypothesis that the metabolic activities of the gut microbiota facilitate the extraction of energy from ingested dietary substances and help store this energy in host adipose tissue for later use. In fact, gut bacterial flora of obese mice and humans include fewer Bacteroidetes and correspondingly more Firmicutes than that of their lean counterparts, suggesting that differences in energy extraction of ingested food substances may be due to the composition of gut $\operatorname{microbiota}^{(37)}$.

In humans, however, it is not known whether whole grains could influence body fat distribution through an effect on gut incretin hormones. Nonetheless, available data in human subjects show that a diet rich in whole-wheat cereals compared with a diet based on bran wheat is able to increase the number of faecal bifidobacteria and lactobacilli, the target genera for prebiotic intake ${ }^{(38)}$.

\section{Conclusions}

(1) The different composition of whole-grain bread and white bread shows inconsistent results regarding its influence on body weight and abdominal fat.

(2) Reducing white bread, but not whole-grain bread, consumption within a Mediterranean-style food pattern setting is associated with lower gains in weight and abdominal fat. However, a definition of whole-grain bread is needed for application in epidemiological studies.

(3) Additional studies using traditional ways of bread production should analyse this effect on weight and metabolic regulation.

\section{Acknowledgements}

The authors thank the participants of the trial for their enthusiastic collaboration and the PREDIMED personnel for their excellent assistance with all aspects of the trial. RETIC PREDIMED RD06/0045 and CIBERobn are initiatives of the Instituto de Salud Carlos III. The authors are also grateful for grant support by the Spanish Minister of Science and Innovation (FI070473) and Centro Nacional de Investigaciones Cardiovasculares Carlos III (CNIC06-2007) and Agencia Canaria de Investigacion, Innovacion y Sociedad de la de la Informacion (Gobierno de Canarias; PI 2007/050).

The authors' contributions are as follows: L. S.-M. and I. B.-C. prepared the manuscript and wrote the paper with important input and feedback between them. Both authors read and approved the final version of the manuscript.

Neither of the authors has any conflict of interest to declare.

\section{References}

1. Romaguera D, Ängquist L, Du H, et al. (2011) Food composition of the diet in relation to changes in waist circumference adjusted for body mass index. PLOS ONE 6, e23384.

2. Trichopoulou A, Costacou T, Bamia C, et al. (2003) Adherence to a Mediterranean diet and survival in a Greek population. $N$ Engl J Med 348, 2599-2608.

3. Trichopoulou A, Kouris-Blazos A, Wahlqvist ML, et al. (1995) Diet and overall survival in elderly people. BMJ 311, 1457-1460.

4. Romaguera D, Norat T, Vergnaud AC, et al. (2010) Mediterranean dietary patterns and prospective weight change in participants of the EPIC-PANACEA project. Am J Clin Nutr $\mathbf{9 2}$, 912-921. 
5. Buckland G, Bach A \& Serra-Majem L (2008) Obesity and the Mediterranean diet: a systematic review of observational and intervention studies. Obes Rev 9, 582-593.

6. Serra-Majem L \& Raido Quintana B (2010) Consumo de pan en el mundo y en España (Bread consumption in the world and in Spain). In Libro Blanco del Pan (Bread's White Book), pp. 63-77 [A Gil and L Serra-Majem, editors]. Madrid: Ed Med Panamericana.

7. WHO (2000) Obesity: Preventing and Managing the Global Epidemic. Report of a WHO Consultation. WHO Technical Report Series no. 894, Geneva.

8. Williams PG, Grafenauer SJ \& O'Shea JE (2008) Cereal grains, legumes, and weight management: a comprehensive review of the scientific evidence. Nut Rev 66, 171-182.

9. Juntunen KS, Niskanen LK, Liukkonen KH, et al. (2002) Postprandial glucose, insulin, and incretin responses, grain products in healthy subjects. Am J Clin Nutr 75, 254-262.

10. Bautista-Castaño I \& Serra-Majem L (2012) Relationship between bread consumption, body weight, and abdominal fat distribution: evidence from epidemiological studies. Nutr Rev 70, 218-233.

11. Tillotson JL, Bartsch GE, Gorder D, et al. (1997) Food group and nutrient intakes at baseline in the Multiple Risk Factor Intervention Trial. Am J Clin Nutr 65, Suppl. 1, 228S-257S.

12. Jacobs DR Jr, Meyer KA, Kushi LH, et al. (1998) Whole-grain intake may reduce the risk of ischemic heart disease death in postmenopausal women: the Iowa Women's Health Study. Am J Clin Nutr 68, 248-257.

13. Greenwood DC, Cade JE, Draper A, et al. (2000) Seven unique food consumption patterns identified among women in the UK Women's Cohort Study. Eur J Clin Nutr 54, 314-320.

14. Cleveland LE, Moshfegh AJ, Albertson AM, et al. (2000) Dietary intake of whole grains. Am Coll Nutr 19, 331S-338S

15. Cho S, Dietrich M, Brown CJ, et al. (2003) The effect of breakfast type on total daily energy intake and body mass index: results from the Third National Health and Nutrition Examination Survey (NHANES III). J Am Coll Nutr 22, 296-302.

16. Moreira P \& Padrão P (2006) Educational, economic and dietary determinants of obesity in Portuguese adults: a cross-sectional study. Eat Behav 7, 220-228.

17. Schulz M, Kroke A, Liese AD, et al. (2002) Food groups as predictors for short-term weight changes in men and women of the EPIC-Potsdam cohort. J Nutr 132, 1335-1340.

18. Schulz M, Nöthlings U, Hoffmann K, et al. (2005) Identification of a food pattern characterized by high-fiber and low-fat food choices associated with low prospective weight change in the EPIC-Potsdam Cohort. $J$ Nutr 135, 1183-1189.

19. Liu S, Willett WC, Manson JE, et al. (2003) Relation between changes in intakes of dietary fiber and grain products and changes in weight and development of obesity among middle-aged women. Am J Clin Nutr 78, 920-927.

20. Halkjaer J, Sørensen TI, Tjønneland A, et al. (2004) Food and drinking patterns as predictors of 6-year BMI-adjusted changes in waist circumference. Br J Nutr 92, 735-748.

21. Togo P, Osler M, Sørensen TIA, et al. (2004) A longitudinal study of food intake patterns and obesity in adult Danish men and women. Int J Obes Relat Metab Disord 28, 583-593.

22. Koh-Banerjee P, Franz M, Sampson L, et al. (2004) Changes in whole-grain, bran, and cereal fiber consumption in relation to 8-year weight gain among men. Am J Clin Nutr 80, $1237-1245$.

23. Halkjaer J, Tjønneland A, Thomsen BL, et al. (2006) Intake of macronutrients as predictors of 5-year changes in waist circumference. Am J Clin Nutr 84, 789-797.

24. Stamler J \& Dolecek TA (1997) Relation of food and nutrient intakes to body mass in the special intervention and usual care groups in the Multiple Risk Factor Intervention Trial. Am J Clin Nutr 65, Suppl. 1, 366S-373S.

25. Bautista-Castaño I, Sánchez-Villegas A, Estruch $\mathrm{R}$, et al. (2012) Changes in bread consumption and 4-year changes in adiposity in Spanish subjects at high cardiovascular risk. Br J Nutr 3, 1-10.

26. Estruch R, Martínez-González MA, Corella D, et al. (2006) PREDIMED study investigators effects of a Mediterranean style diet on cardiovascular risk factors: a randomised trial. Ann Intern Med 145, 1-11.

27. Martínez-González MA, Corella D, Salas-Salvadó J, et al. (2012) Cohort profile: design and methods of the PREDIMED study. Int J Epidemiol 41, 377-385.

28. Fardet A (2010) New hypotheses for the health-protective mechanisms of whole-grain cereals: what is beyond fibre? Nutr Res Rev 23, 65-134.

29. Giacco R, Della Pepa G, Luongo D, et al. (2011) Whole grain intake in relation to body weight: from epidemiological evidence to clinical trials. Nutr Metab Cardiovasc Dis 21, 901-908.

30. Loria Kohen V, Gómez Candela C, Fernández Fernández C, et al. (2011) Impact of two low-calorie meals with and without bread on the sensation of hunger, satiety and amount of food consumed. Nutr Hosp 26, 1155-1160.

31. Bornet FR, Jardy-Gennetier AE, Jacquet N, et al. (2007) Glycaemic response to foods: impact on satiety and long-term weight regulation. Appetite 49, 535-553.

32. Du H, van der ADL, van Bakel MM, et al. (2009) Dietary glycaemic index, glycaemic load and subsequent changes of weight and waist circumference in European men and women. Int J Obes (Lond) 33, 1280-1288.

33. McKeown NM, Troy LM, Jacques PF, et al. (2010) Whole- and refined-grain intakes are differentially associated with abdominal visceral and subcutaneous adiposity in healthy adults: the Framingham Heart Study. Am J Clin Nutr 92, $1165-1171$.

34. Giacco R, Lappi J, Costabile G, et al. (2013) Effects of rye and whole wheat versus refined cereal foods on metabolic risk factors: a randomised controlled two-centre intervention study. Clin Nutr 6, 941-949.

35. Weickert MO \& Pfeiffer AF (2008) Metabolic effects of dietary fiber consumption and prevention of diabetes. J Nutr 138, 439-442.

36. Burton-Freeman BM \& Keim NL (2008) Glycemic index, cholecystokinin, satiety and disinhibition: is there an unappreciated paradox for overweight women? Int $J$ Obes (Lond) 32, 1647-1654.

37. Di Baise JK, Zhang H, Crowell MD, et al. (2008) Gut microbiota and its possible relationship with obesity. Mayo Clin Proc 83, 460-469.

38. Costabile A, Klinder A, Fava F, et al. (2008) Whole-grain wheat breakfast cereal has a prebiotic effect on the human gut microbiota: a double blind, placebo-controlled, crossover study. Br J Nutr 99, 110-120. 